\title{
Analyzing the Coordination Relationship between Urban Built Environment and Traffic Level
}

\author{
Tian Li $\mathbb{D}^{1,2}$ Haobin Jiang ${ }^{10},{ }^{1}$ Peng Jing, ${ }^{1}$ and Mengmeng Zhang ${ }^{2}$ \\ ${ }^{1}$ School of Automotive and Traffic Engineering, Jiangsu University, Zhenjiang, Jiangsu 212013, China \\ ${ }^{2}$ School of Transportation and Logistics Engineering, Shandong Jiaotong University, Jinan 264209, China \\ Correspondence should be addressed to Haobin Jiang; jianghb@ujs.edu.cn
}

Received 31 March 2021; Accepted 3 June 2021; Published 11 June 2021

Academic Editor: Tomio Miwa

Copyright (c) 2021 Tian Li et al. This is an open access article distributed under the Creative Commons Attribution License, which permits unrestricted use, distribution, and reproduction in any medium, provided the original work is properly cited.

The coordination relationship between urban built environment and transport system is an indispensable field in the study of urban planning. Recent research efforts in built environment and transport system have focused on the effects of built environment on travel behaviors, such as car ownership, choice of travel mode, and travel frequency. These travel behaviors will affect the traffic level. However, research studies on direct assessments of links between built environment and traffic level are still limited. This paper aims to fill this gap by modeling with data envelopment analysis based on Point of Interest (POI) data and floating car data collected in Jinan, China. It is found that the coordination relationship between built environment and traffic level is poor in Jinan. With regard to the built environment input index, the distance from the city center has the greatest influence on the coordination relationship. And for the built environment output index, bus stop influences the coordination relationship most significantly. This research can support the provision of quantitative basis for the formulation of governance priorities for traffic governance policies.

\section{Introduction}

There is a complex interaction between urban built environment and urban traffic in the aspects of correlation, mutual, symbiosis, and coordination [1]. A stable dynamic equilibrium state is achieved between them through a cyclic feedback. Traffic accidents, traffic congestion, noise pollution, air pollution, unreasonable land use, and other problems are serious challenges in the process of urbanization $[2,3]$. These problems are caused by the incongruous relationship between the built environment and the transport system. Therefore, it is necessary to study the coordination relationship between built environment and traffic level to promote the harmonious and sustainable development of urban society.

Based on the analysis of traffic and land use data, Mitchell and Rapkin found that traffic is closely related to land use, thus attracting a large number of scholars to study the relationship between urban traffic and land use [4]. The research of Stover and Koepke found that there is a two-way feedback effect between urban traffic and land use [5]. Handy analyzed the impact of land use on travel characteristics and studied the integrated development planning of land use and transport systems from the perspective of smart cities [6]. With the research further developing, many scholars focused on the coordination relationship between land use and transport system from the view point of promoting benign urban development. Black studied the sustainability of land use and transport system from the perspective of the integration of transportation and land use [7]. Frank studied the coordination between land use and transport system to promote walking and cycling [8].

After the mid-1980s, due to the constraints of natural environment and other factors, it is impossible for some big cities in Europe and America to expand their urban roads without restriction. An increasing number of researchers began to pay attention to the relationship between urban built environment and travel mode choice and began to consider how to change the urban 
environment to reduce the use of cars. Cervero and Kockelman analyzed the impact of built environment 3D (Density, Diversity, and Design) on travel distance and travel mode using the traffic survey log data of San Francisco Bay Area [9]. They found that the built environment with high density and high degree of mixing and grid street network has a significant impact on reducing travel distance and encouraging nonmotorized travel. Handy studied the relationship between built environment and walking and cycling and believed that the attraction of walking and cycling should be improved through more friendly street connection and design [10]. Ewing and Cervero studied the impact of built environment on travel behavior and travel self-choice behavior [11]. Liu et al. studied the influence mechanism of different built environment variables on car ownership [12].

In the above study, the land use mostly refers to the spatial distribution of various social activities, such as industrial areas, residential areas, and commercial areas [13-15]. The transport system mainly includes transportation structure and transportation infrastructure. Transportation structure refers to various transportation modes and their proportion, while transportation infrastructure includes road network and parking facilities.

However, land use and transport system are not two completely parallel dimensions $[16,17]$. Urban transport system is an essential part of the city. The safety and efficiency of the transport system are not only affected by the land use but also by urban design and transportation infrastructure. For example, the density of public transportation network is an element of the transport system but also has a profound impact on transportation efficiency. And the representation of the transport system only from traffic structure and traffic infrastructure cannot fully reflect the operating efficiency and safety of the transport system. For example, the high density of the road network does not mean that the operation efficiency of the transport system is high. Therefore, it is necessary to study the coordination relationship between urban built environment and traffic level from a higher dimension. In the existing research on the relationship between built environment and transport system, scholars mostly focus on the impact of built environment on traffic behaviors which include travel mode, frequency, distance, time, purpose, and travel chain. However, the direct assessments of links between built environment and traffic level are still rare. These traffic behaviors will eventually affect the traffic level.

This paper studies the coordination relationship between urban built environment and traffic level. On the one hand, it can evaluate the coordination degree of urban built environment and transport system from the perspective of safety and efficiency, and it can promote the understanding of the relationship between urban built environment and transport system more comprehensively and deeply. On the other hand, it can find out the incongruent factors in two systems to make the urban planning and traffic planning policies more targeted.

\section{Methodology}

2.1. Study Area and Data Source. The research is based on a case study in Jinan, China. We choose the area within the ring expressway as the study area (see Figure 1). This area is the main urban area of Jinan. Grid management is a new active urban administration. Grid divide scientifically is the core link of giving full play to its superiority. As the main part of city management, traffic management can also adopt the idea of grid division because this method can reduce the amount of information calculation greatly, simplify the complexity of algorithm, and improve the timeliness of decision-making. In order to derive the complex relationship between built environment and traffic level, the research area is divided into $2 \mathrm{~km}^{*} 2 \mathrm{~km}$ square grids as unit inspired by the idea of grid division in urban grid management and urban traffic research $[18,19]$.

The built environment data are collected from API data disclosed by AutoNavi in 2019, and the traffic congestion data and traffic accident data are from the Traffic Big Data Bureau of Jinan. The traffic congestion data are represented by traffic operation index, and the traffic accident data take the average value of the weekly accident after eliminating the abnormal value of the annual accident data.

2.2. Data Envelopment Analysis (DEA). Although the studies on the coordination relationship between built environment and traffic level are few, there are many research studies on the coordination relationship between land use and transport system. The applied models mainly include parameter method, analytic hierarchy process, coupling model, and DEA model [20-23]. The parameter method and coupling model measure the coordinated level of transportation and land use from macro and overall perspectives, but they are weak in reflecting the interaction between them. Although the analytic hierarchy process takes into account the policy and environmental factors, it has strong subjectivity.

The DEA model does not need to give the weight of index in advance and is not affected by the dimension of the index and can show the interaction of the two systems through mutual input and output. The process of interaction between built environment and traffic level is regarded as the process of input and output. Measuring the coordination relationship between built environment and traffic level can not only study two systems from a holistic angle but also can study the constraints factors from the internal indicators. Therefore, this paper chooses the DEA model as the evaluation model.

2.2.1. DEA Model. The DEA model is a nonparametric technical efficiency analysis method based on the comparison between the evaluated objects. It was first proposed by American scholars Charnes, Cooper, and Rhodes in 1978. It is not affected by the input-output data measurement unit, and the model weight in DEA is generated by mathematical programming according to the data, so there is no need to set the weight in advance, which eliminates the subjective interference. The basic idea of the DEA model includes four parts: determination of decision-making unit (DMU), 


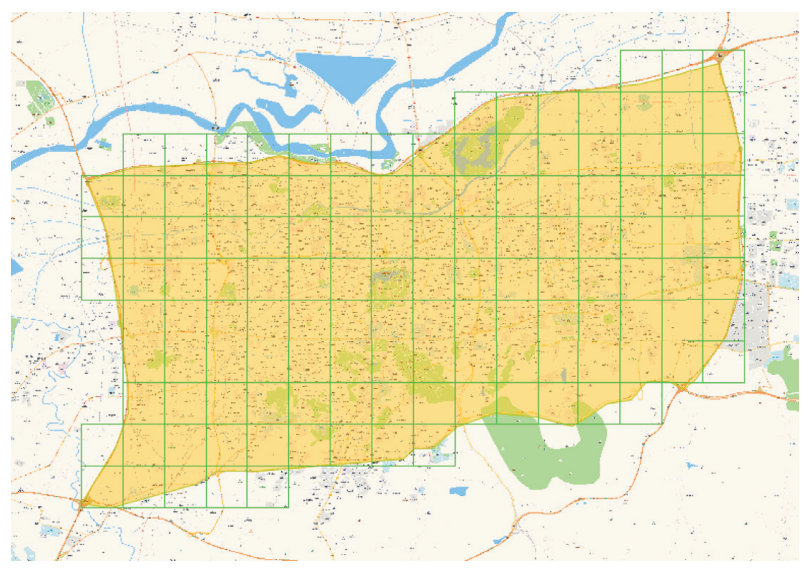

Figure 1: Study area of this paper.

establishment of the index system, selection of the DEA evaluation model, and evaluation analysis.

The number of DMUs should not be less than the product of the number of input indicators and output indicators and should not be less than 2 times of the sum of the number of input indicators and output indicators [24].

There are five basic models commonly used in DEA: $C^{2} R, B C^{2}, C^{2} G S^{2}, C^{2} W$, and $C^{2} W H$. Among them, the $C^{2} R$ model is intuitive in the evaluation of the effectiveness of indicators and the calculation of contribution rate, so this paper chooses the $C^{2} R$ model [25-28].

The main evaluation process is described as follows.

Suppose that there are $n \operatorname{DMU}$, and each $\operatorname{DMU} j(J=1,2$, .., $N$ ) has $m$ inputs and $s$ outputs. $x_{i j}$ is the number of $i$-th input in DMUj, and $x_{i j}>0 . y_{\mathrm{r} j}$ is the number of $r$-th output in DMUj, $v_{i}$ is the importance weight of $i$-th input, and $u_{r}$ is the importance weight of $r$-th output. $\varepsilon$ is a non-Archimedean infinitesimal, and $\varepsilon>0$. The DEA model with nonArchimedean infinitesimal can be seen as follows:

$$
\left\{\begin{array}{l}
\max u^{T} y_{0} \\
w^{T} x_{j}-u^{T} y_{j} \geq 0, j=1, \ldots n ; w^{T} x_{0}=1, \\
w \geq \varepsilon e, u \geq \varepsilon \hat{e} .
\end{array}\right.
$$

Then, equation (2) is obtained from equation (1) by Charness-Cooper transformation.

$$
\left\{\begin{array}{l}
\min \left[\theta-\varepsilon\left(e^{T} s^{-}+\hat{e}^{T} s^{+}\right)\right] \\
\sum_{j=1}^{n} x_{j} \lambda_{j}+s^{-}=\theta x_{0} \\
\sum_{j=1}^{n} y_{j} \lambda_{j}-s^{+}=y_{0} \\
\lambda_{j} \geq 0, j=1, \ldots, n \\
s^{+} \geq 0, s^{-} \geq 0
\end{array}\right.
$$

where $\theta$ is the coordinated development index of built environment and transportation, $\varepsilon$ is a non-Archimedean infinitesimal, $s^{-}$is the relaxation variable of the input term, and $s^{+}$is the relaxation variable of the output term. $\theta^{0}$, $\lambda_{j}^{0},\left(j=1, \ldots, n, s^{0+}, s^{0-}\right)$ is the optimal solution of the model. If $\theta^{0}<1$, then DMUj0 is DEA invalid, and the input and output indexes need to be adjusted to improve the coordination level. If $\theta^{0}=1$ and $e^{T} s^{-}+\widehat{e}^{T} s^{+}=0$, then the DMUj0 is DEA efficient, which shows that the output and input resources are fully utilized. If $\theta^{0}=1, e^{T} s^{-}+\widehat{e}^{T} s^{+}>0$, then the DMUj0 is weekly efficient in DEA, which means it is necessary to adjust another index while keeping the input or output unchanged, so as to improve the coordination level.

The level of coordinated development is related to the value of $\theta$. The closer $\theta$ is to 1 , the higher the level of coordinated development is, and vice versa.

\subsubsection{Evaluation Analysis}

(1) Determination of Coordinated Development Level. Due to the two-way interactive feedback relation between built environment and transport system, the indicators of built environment and transport system are input and output to each other when evaluating the coordination relation.

Taking the built environment as the input index and the traffic level as the output index, the drive of the built environment to promote the traffic level is regarded as a production process, and the coordinated development index of the built environment to the traffic level is obtained, designated $\theta=\left(\theta_{1}, \theta_{2}, \ldots \theta_{n}\right)$. Similarly, the coordinated development index of traffic level to built environment is designated as follows: $\theta^{\prime}=\left(\theta_{1}^{\prime}, \theta_{2}^{\prime}, \ldots \theta_{n}^{\prime}\right)$. The membership function is used to evaluate the coordination between the two systems. The calculation formula is shown as follows:

$$
u=\frac{\min \left(\theta, \theta^{\prime}\right)}{\max \left(\theta, \theta^{\prime}\right)}
$$

where $u$ is the level of coordinated development between the two systems.

(2) Influence of One Index on DMU. If the evaluation index system is recorded as $D$, the index system is recorded as $\mathrm{Di}$ after the $i$-th index is removed.

The influence of $i$-th index on traffic level is shown in equation (4). And the influence of $i$-th index on built environment is shown in equation (5).

$$
\begin{aligned}
& S_{j}(i)=\frac{\theta_{j}(D)-\theta_{j}\left(D^{i}\right)}{\theta_{j}\left(D^{i}\right)}, \\
& S_{j}^{\prime}(i)=\frac{\theta_{j}^{\prime}(D)-\theta_{j}^{\prime}\left(D^{i}\right)}{\theta_{j}^{\prime}\left(D^{i}\right)},
\end{aligned}
$$

where $S_{j}(i)$ is the influence of $i$-th index on traffic level, $S_{j}^{\prime}(i)$ is the influence of $i$-th index on built environment, $\theta_{j}(D)$ and $\theta_{j}^{\prime}(D)$ are the coordinated development indexes of the $j$ th DMU under the $D$ index system, and $\theta_{j}\left(D^{i}\right)$ and $\theta_{j}^{\prime}\left(D^{i}\right)$ are the coordinated development indexes of the $j$-th DMU under the $D i$ index system.

If $\mathrm{DMU}_{j}$ meets the requirement of $S_{j 0}(i)=\max S_{j}(i)$, it shows that the change range of coordinated development 
index is the largest after index $i$ is added. If $i$ is the input indicator, it means that there is too little input or the $i$-th index has the utilization advantage; if $i$ is the output indicator, it means that it is more focused on the output capability represented by the $i$-th indicator.

\subsection{Variable Selection and Description}

2.3.1. Built Environment Variable. Built environment is the product of human civilization, which usually consists of three parts: land use mode, urban design, and transport system [10, 29-31]. Land use pattern is the spatial distribution of various social activities, which can be divided into industrial area, residential area, commercial area, and so on. Urban design focuses on the spatial arrangement of various elements in the city, as well as the function and attraction of streets and public space. The transport system refers to the quality provided by various infrastructures [32]. In the field of built environment and transport system, built environment is usually described by the following five main elements: density, diversity, design, distance to transit, and destination accessibility $[33,34]$. In this paper, combined with the universality and availability of indicators used in previous studies, five indicators are selected: population density, land use mix degree, road network density, distance to the city center, and bus stop density, which are shown in Table 1.

The description of indicators in this paper is shown in Figures 2-5. It can be seen from Figure 2 that the characteristics of population distribution in Jinan are distinct, high in the middle, and low in the surrounding. The population density is averaged according to the population density of the neighborhood offices covered in the grid.

The degree of land use mix in Jinan is shown in Figure 3. The degree of land use mix is measured by Herfindahl-Hirschman index (HHI). The higher the HHI, the lower the degree of land use mix. The smaller the HHI, the higher the degree of land use mix $[35,36]$.

The road network density is calculated according to the road network length of each grid. The road network density is distributed in a zonal pattern, with the density high in the middle and low in the north and south sides (see Figure 4). It is related to the zonal urban distribution state of Jinan.

The density distribution of bus stops is similar to that of road network density (see Figure 5). The distance to the city center is shown in Figure 6, and this paper takes Quancheng Square as the center of the city. The distance to the city center refers to the straight-line distance between the center point of each grid and Quancheng Square.

2.3.2. Traffic Level Variable. Traffic level refers to the safety level and efficiency level of the urban transport system. In this paper, the safety level is represented by traffic accident index, while the traffic efficiency level is represented by traffic index. The traffic index is calculated by dividing the actual travel time consumption by the free flow travel time consumption. The smaller the traffic index is, the better the traffic condition is, and vice versa. Figure 7 shows that the traffic index in the middle part of the study area is higher and that in the surrounding area is lower. The traffic accident rate is high in the middle area and lower in the surrounding (shown in Figure 8).

\section{Results and Discussion}

3.1. Analysis of Coordination Index and Coordinated Development Level. Deap 2.1 is used to calculate the coordinated development index and coordinated development level of built environment and traffic level in the study area of Jinan according to equations (2) and (3). Then, they were classified into 4 grades as shown in Table 2 according to the grading standard of similar research [37].

Figures 9 and 10 show the distribution and proportion of coordinated development index of built environment to traffic level. The proportion of fully coordinated area accounts for $22 \%$ and is mainly distributed in peripheral areas such as Jinan Huaiyin interchange and Dougou village and important scenic spots in the urban area such as Daming Lake, Mount Qianfo, and Huashan Park. Coordinated area and approximately coordinated area accounted for $31 \%$ and $22 \%$, respectively, and are distributed around the fully coordinated area. It shows that the built environment of these areas supports and promotes the development of traffic level. Because the population density of the surrounding area is low and the traffic is relatively smooth, the mixed degree of land use and the road network density around the scenic area is high, and the public transportation is developed, and basic facilities are perfectly, so the support for the traffic level is high. $19 \%$ of the study area is uncoordinated, mainly distributed along Aoti Road (middle), Second Ring West Viaduct, and Longao North Road. In these areas, the separation of work and housing is serious, and the land mix is low, which easily leads to tidal traffic congestion, so the coordinated development index of traffic level is low.

Figures 11 and 12 show the distribution and proportion of coordinated development index of traffic level to built environment. The proportion of fully coordinated area accounts for $9 \%$ and is mainly distributed around Jingqi Road and Qilu Software Park. Coordinated and approximately coordinated regions accounted for $12 \%$ and 39\%, respectively, and are mainly distributed in the central and eastern regions. In recent years, through a series of traffic management policies, such as the construction of traffic brain, intelligent signal control, and investigation of traffic hidden danger points, the traffic level of the central and eastern region of Jinan has been improved, and the land use type, road network density, and bus stop density are more reasonable. Therefore, the coordinated and approximately coordinated areas are concentrated in the central and eastern region. However, the construction and development of the western region are relatively late, and the policy and effect of improving the transportation level lagged behind the central and western regions, so the feedback effect of the transportation level on the built environment is weak.

Figures 13 and 14 show the distribution and proportion of coordinated development level of two systems. The proportion of fully coordinated region is $0 \%$. The proportion of coordinated and basically coordinated areas was $37 \%$ and 
TABLE 1: The selection of built environment variable.

\begin{tabular}{lcc}
\hline Variable & Main indicators in previous studies & Indicators in this paper \\
\hline Density & Population density, employment density, or office building density & Population density \\
Diversity & The degree of land mix, the degree of job housing balance & The degree of land mix \\
Design & Intersection density, road network density, road mileage & Road network density \\
Distance to transit & Bus stop density, distance from bus stop, or bus network density & Bus stop density \\
Destination accessibility & Accessibility of workplace, CBD, or point of interest & Distance to the city center \\
\hline
\end{tabular}
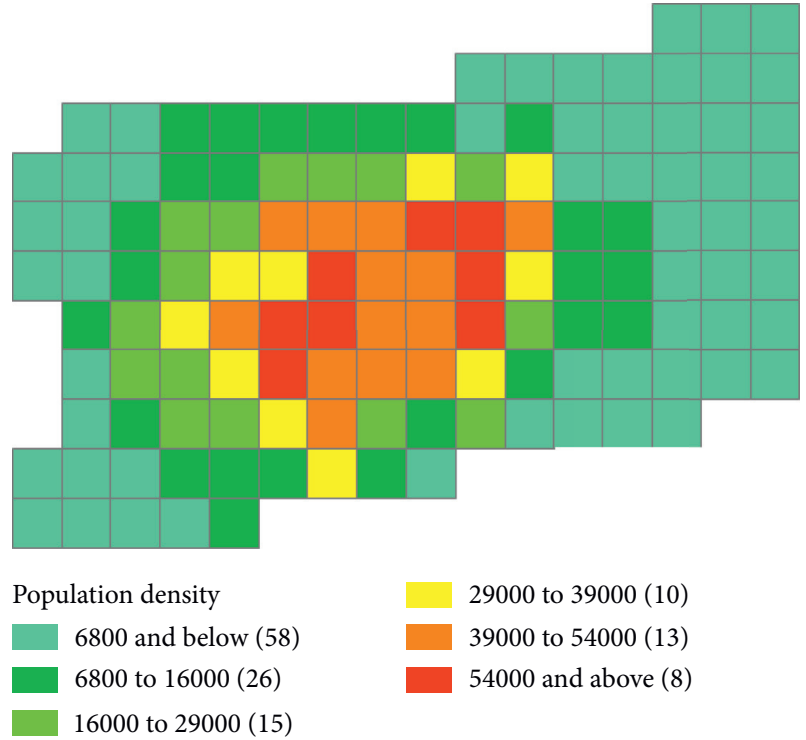

Figure 2: Population density (unit: people per square mile).

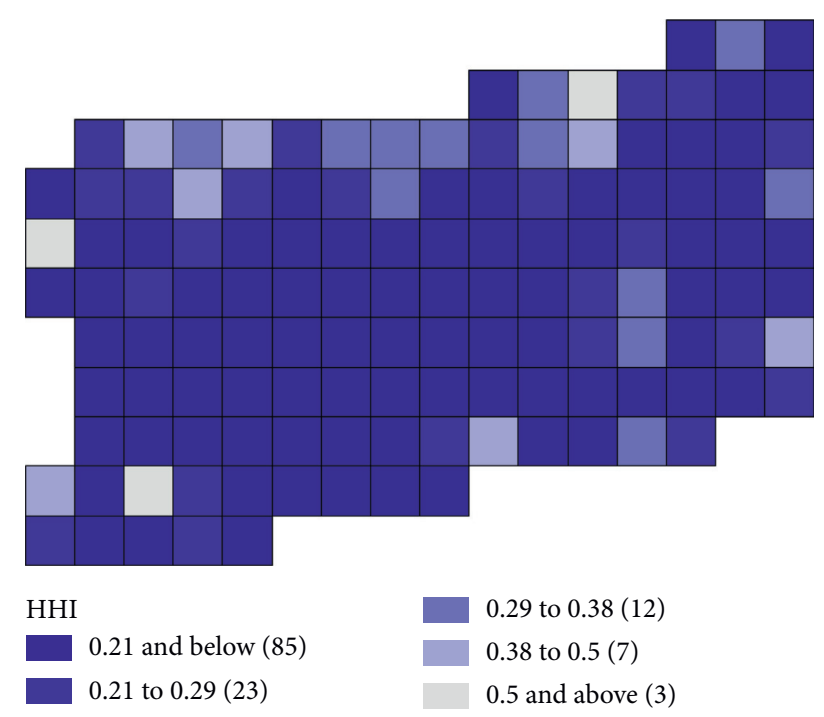

Figure 3: The degree of land mix (HHI).

$38 \%$, respectively, and the spatial distribution was relatively scattered. The proportion of uncoordinated areas was $25 \%$, mainly concentrated in the vicinity of Qilu Software Park, Nanxinzhuang road, and Huashan Park. It is a pity that Jinan has not built an area where the built environment and traffic level are fully coordinated. The main reason is that limited by the natural conditions, the urban land of Jinan is distributed in the east-west belt, forming a single center layout. The

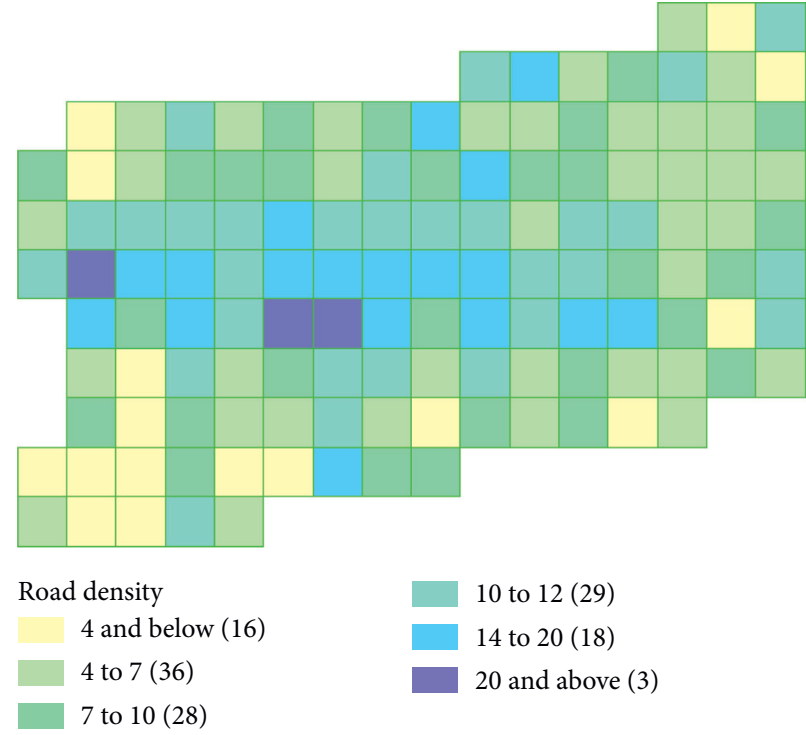

FIGURE 4: Road network density (unit: km/square mile).

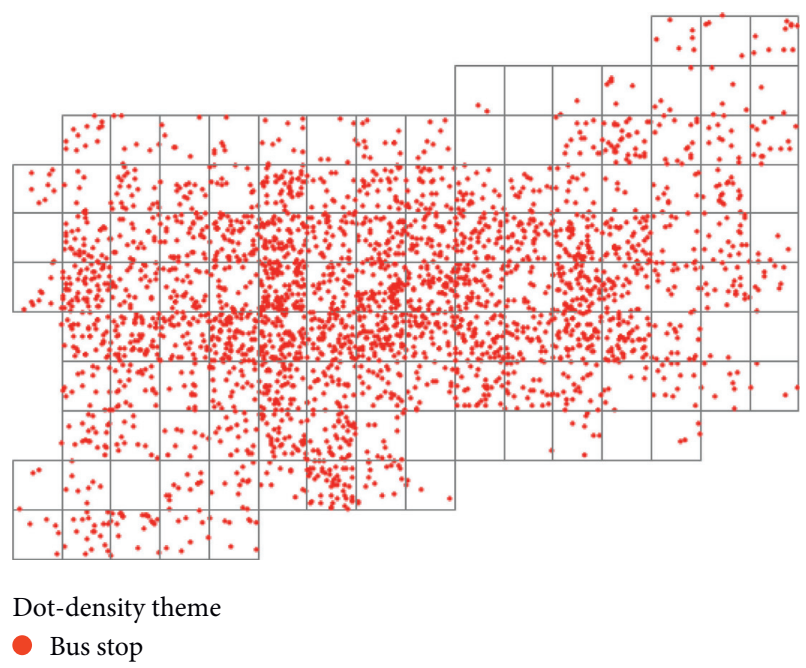

FIGURE 5: Bus stop density (unit: point/square mile).

traffic also presents the characteristics of east-west traffic flow concentration and high traffic pressure on the trunk road. The urban traffic and built environment have not formed a very good coordination relation.

3.2. Analysis on the Reasons of Non DEA Efficiency. In order to explore the reasons why the traffic level and built environment cannot achieve coordinated development, we 


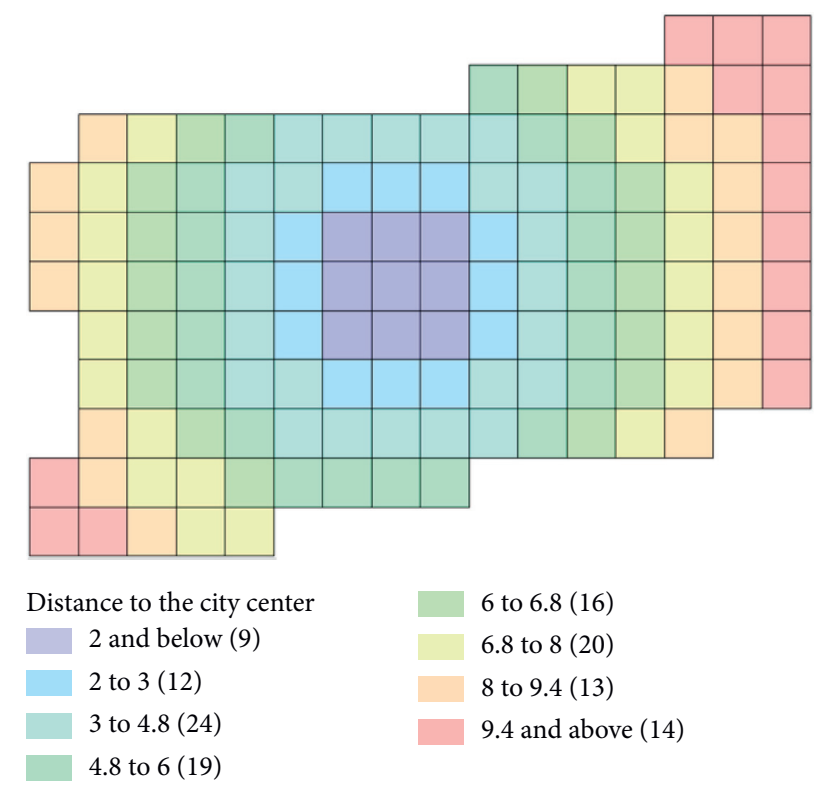

Figure 6: Distance to the city center (unit: mile).

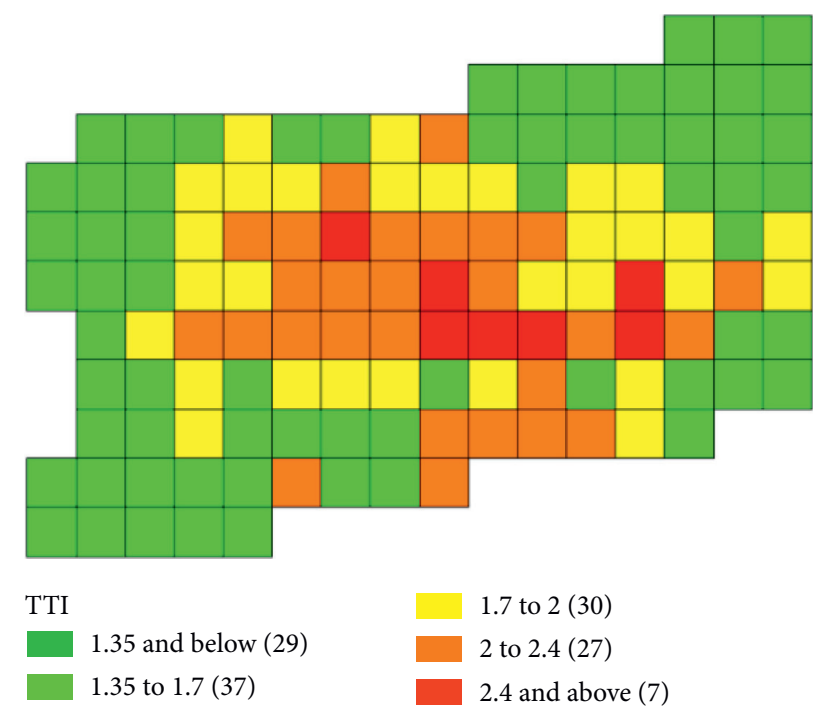

Figure 7: Traffic index.

calculated $S_{j}(i)$ and $S_{j}^{\prime}(i)$ using formulas (4) and (5). The results are shown in Table 3. The results of grid whose coordinated development level is 1 are shown in Table 4 .

Among the built environment input indicators, the distance from the city center is the largest, which shows that the single core urban layout of Jinan restricts the coordinated development of built environment and traffic level. Quancheng Square is the core area of Jinan City, which integrates the commerce, culture, tourism, and politics. Although the multicentral pattern of Jinan is increasingly prominent, the core area represented by Quancheng Square still occupies a dominant position in the spatial structure of Jinan.

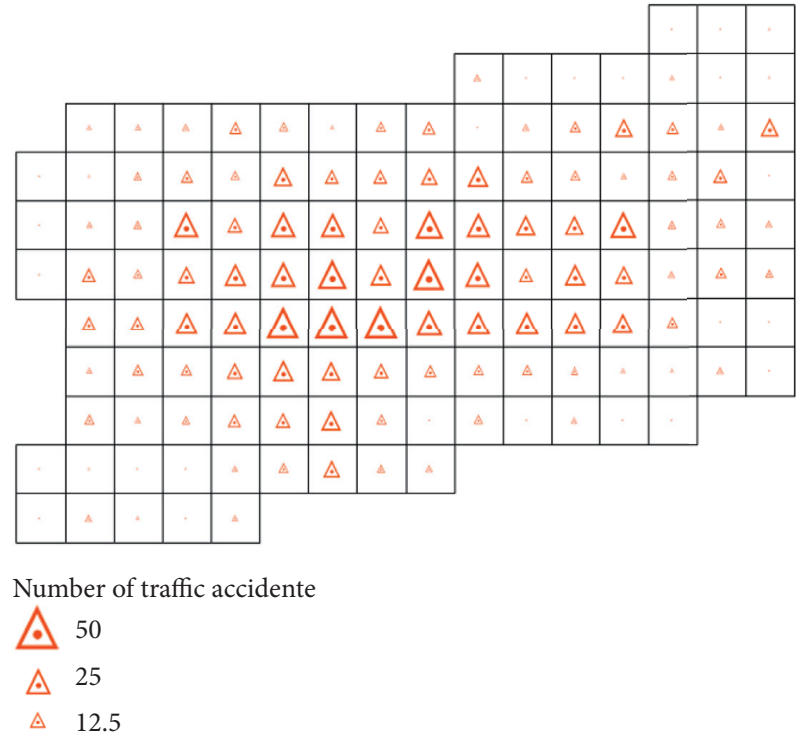

Figure 8: Traffic accident.

The second largest cumulative value is the road network density, which indicates that the uneven distribution of road network density in Jinan also restricts the coordinated development of built environment and traffic level. Jinan is an east-west belt structure city with large traffic flow in the eastwest direction, while the main roads in the east-west direction are Jingshi Road, Beiyuan Street, and outer ring road, which bear greater traffic pressure.

In the output indicators of traffic level, the traffic index has the largest cumulative influence, while the traffic accident volume is smaller, and there is a large gap between them. It shows that the built environment has a greater impact on the traffic state but less impact on traffic accidents. It shows that the impact of built environment on traffic level is mainly reflected in the change of traffic index, and the factors such as population density, land use mix, road network density, and bus stop density will directly affect the traffic index. The impact of built environment on traffic accidents is small, but when the traffic index is good, it will indirectly promote the reduction of traffic accidents.

In the input index of traffic level, the traffic index has the largest cumulative influence, which indicates that traffic congestion is one of the main problems restricting the coordinated development of urban traffic level and built environment. In the built environment output index, the largest cumulative value is the bus stop density and the smallest is the road network density, which indicates that the more significant impact of traffic level fluctuation on the built environment is first reflected in the bus stop density. Because in terms of traffic management policy, vigorously developing public transport is a more powerful means, and the implementation scheme is flexible, low cost, and fast rewarding. The cumulative value of road network density is the smallest mainly because the road network construction 
TABle 2: Four grades of coordinated development index and coordinated development level.

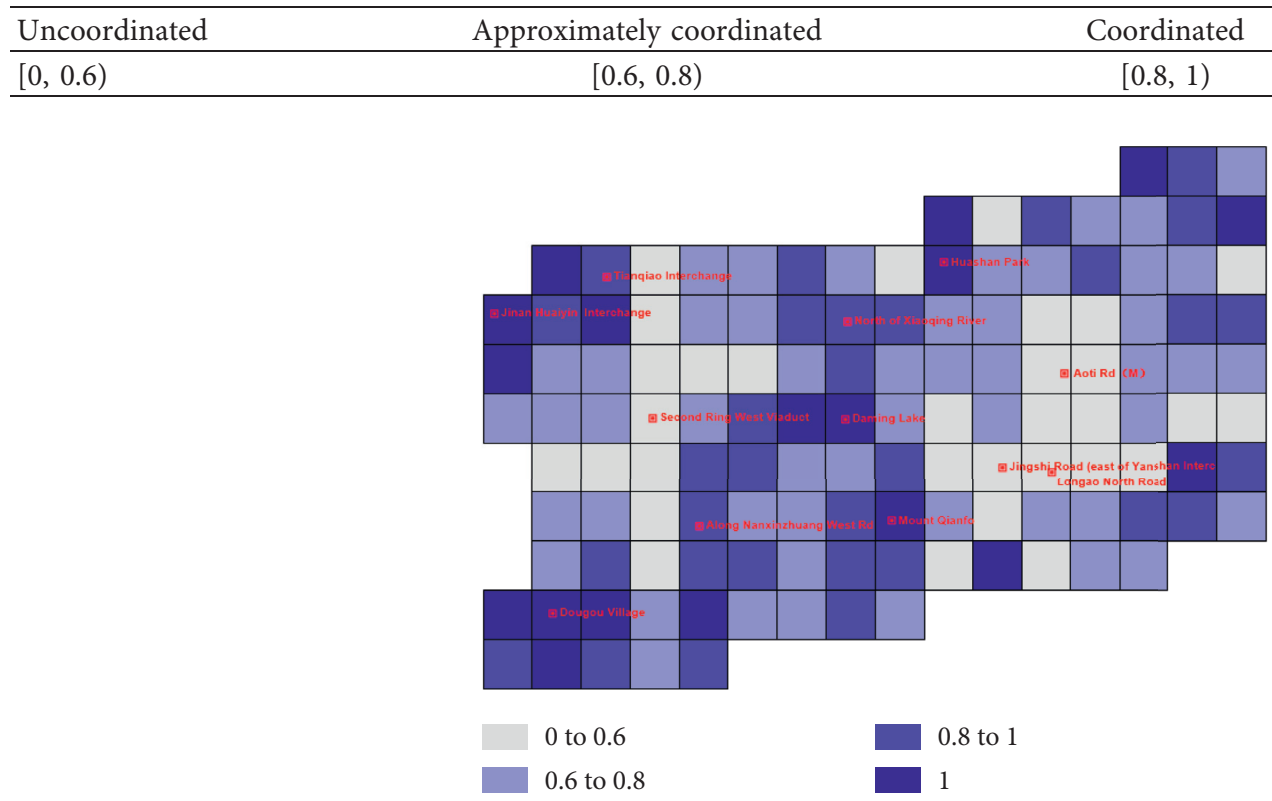

Figure 9: Distribution of coordinated development index $\theta$ of built environment to traffic level.

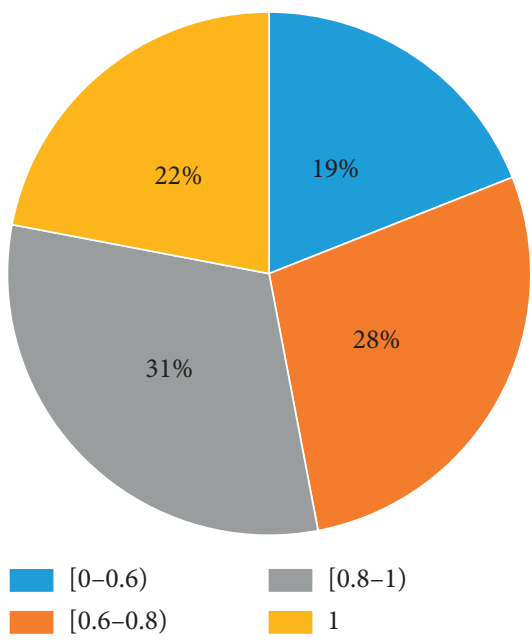

Figure 10: Proportion of coordinated development index of built environment to traffic level.

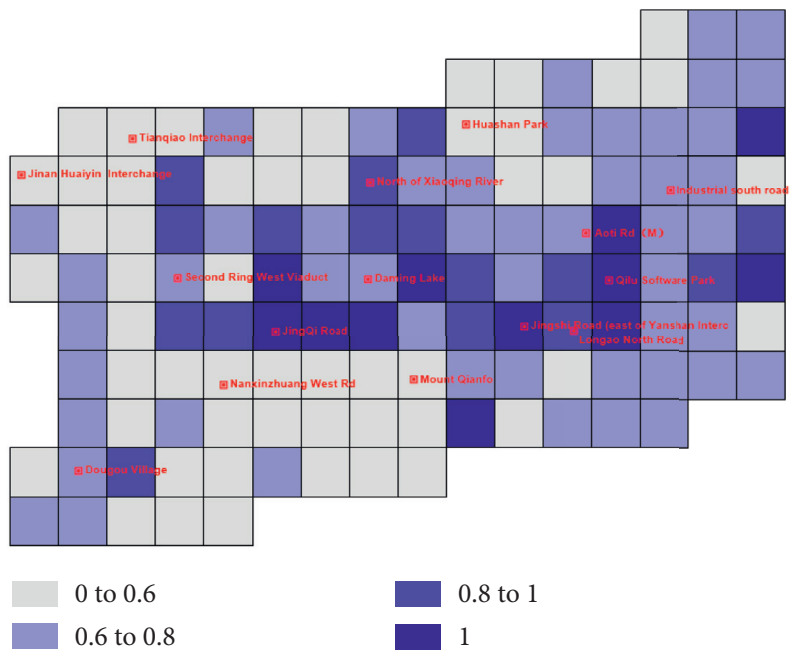

FIGURE 11: Distribution of coordinated development index $\theta^{\prime}$ of traffic level to built environment. 


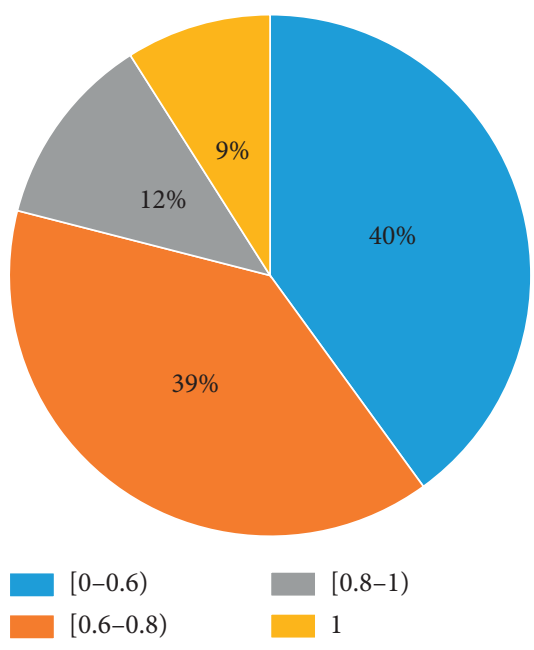

Figure 12: The proportion of coordinated development index $\theta^{\prime}$ of traffic level to built environment.

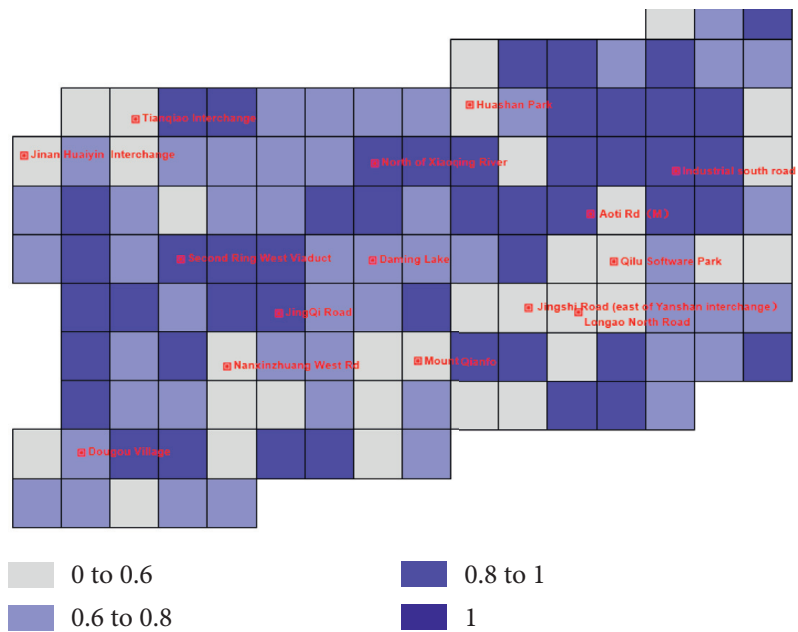

FIgURE 13: The distribution of coordinated development level $u$ of two systems.

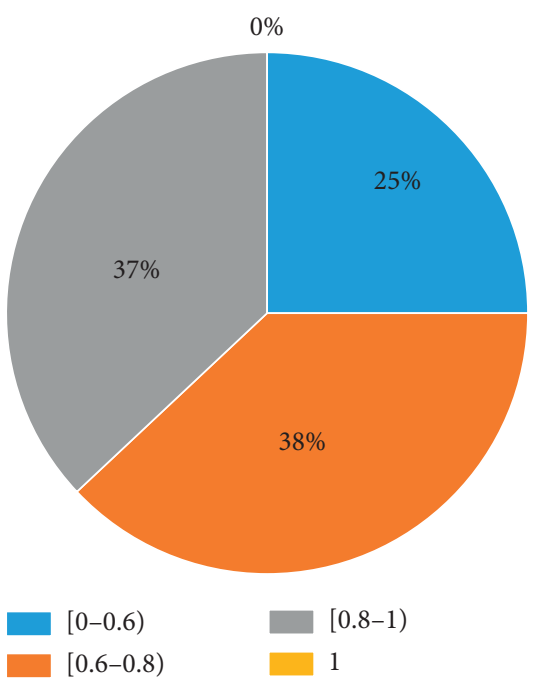

FIgURE 14: The proportion of coordinated development level $u$ of two systems. 
TABLE 3: The sum of $S_{j}(i)$ and $S_{j}^{\prime}(i)$.

\begin{tabular}{lccccccc}
\hline Variable & $\begin{array}{c}\text { Population } \\
\text { density }\end{array}$ & Diversity & $\begin{array}{c}\text { Road network } \\
\text { density }\end{array}$ & $\begin{array}{c}\text { Bus stop } \\
\text { density }\end{array}$ & $\begin{array}{c}\text { Distance to the city } \\
\text { center }\end{array}$ & $\begin{array}{c}\text { Traffic } \\
\text { index }\end{array}$ & $\begin{array}{c}\text { Traffic } \\
\text { accident }\end{array}$ \\
\hline$\sum_{j=1}^{130} S_{j}(i)$ & 4.26 & 7.95 & 11.75 & 18.76 & 1.73 & 121.95 & 0.48 \\
$\sum_{j=1}^{j 3} S_{j}^{\prime}(i)$ & 7.03 & 6.16 & 0.97 & 5.34 & 9.67 & 76.36 & 4.78 \\
\hline
\end{tabular}

TABLe 4: The sum of $S_{j}(i)$ and $S_{j}^{\prime}(i)$ of grid whose coordinated development level is 1 .

\begin{tabular}{lccccccc}
\hline Variable & $\begin{array}{c}\text { Population } \\
\text { density }\end{array}$ & Diversity & $\begin{array}{c}\text { Road network } \\
\text { density }\end{array}$ & $\begin{array}{c}\text { Bus stop } \\
\text { density }\end{array}$ & $\begin{array}{c}\text { Distance to the city } \\
\text { center }\end{array}$ & $\begin{array}{c}\text { Traffic } \\
\text { index }\end{array}$ & $\begin{array}{c}\text { Traffic } \\
\text { accident }\end{array}$ \\
\hline$\sum_{i=1}^{29} S_{j}(i)$ & 0.91 & 2.37 & 4.22 & 7.58 & 0.56 & 20.95 & 0.19 \\
$\sum_{j=1}^{1} S_{j}^{\prime}(i)$ & 1.32 & 2.21 & 0.23 & 1.29 & 2.3 & 8.9 & 1.27 \\
\hline
\end{tabular}

and renewal is a relatively long-term process, especially the current urban land saturation in Jinan, with the road network having not much construction space.

\section{Conclusion}

The coordination and interaction between built environment and traffic level are conducive to promoting the harmonious and sustainable development of the city. At present, few scholars study the coordination relation between built environment and traffic level. In this paper, by constructing the DEA model and conducting a case study in Jinan, we have reached the following conclusions:

(1) In terms of overall coordination, built environment and traffic level of Jinan did not form a good coordination relation mainly because of the inherent belt urban spatial pattern resulting in the traffic pressure in the east-west region. In the process of urban renewal and construction, we can strengthen the traffic construction in east-west region, such as accelerating the east-west rail transit construction, in order to alleviate of traffic pressure.

(2) In terms of index influence, the distance to the city center has the greatest influence in the built environment investment index. Therefore, in the future, Jinan should continue to adhere to the principle of "strong in the East (scientific research strength and industrial upgrading in the East), rise in the West (revitalization of the West Railway Station Area), beautify the South (protection of the southern mountainous area), construct the North (promoting the construction of the northern region), and optimize the central region (optimizing the urban texture of the central urban area)," to improve the pattern of single center city. In the built environment output index, the cumulative impact value of bus stops is the largest, so it is necessary to vigorously develop public transport, advocate public transport travel, and improve public transport service level.

(3) In terms of spatial distribution of coordination index, the fully coordinated areas of built environment to traffic level are concentrated in the peripheral areas of the city and important scenic spots, and the uncoordinated areas are concentrated along Aoti Road (middle), Second Ring West Viaduct, and Longao North Road. In order to improve the coordination index of the built environment to the traffic level, we can increase the posts density and improve the land mixing degree to alleviate the separation of work and housing. The uncoordinated areas of traffic level to built environment are mainly distributed in the western region. Therefore, the positive feedback of traffic level to built environment can be improved by improving traffic congestion and investigating traffic hidden danger points.

(4) Observing the importance of each factor in the fully coordinated grid can provide a quantitative basis for traffic management and traffic evaluation. In order to improve the traffic level, the focus of investment in the built environment can be based on the population $6 \%$, the diversity $15 \%$, the road network density $27 \%$, the bus stop density $50 \%$, and the distance to the city center $4 \%$. In order to strengthen the role of the transportation system in promoting the built environment, the proportion of traffic efficiency and traffic safety can be implemented at $87 \%$ and $13 \%$ in traffic management or traffic evaluation.

To enlighten the future research, the limitations of this paper should be noted as follows:

(1) Study the coordination relation between built environment and traffic level from the time series. This paper studies the coordination relation of two systems only from the perspective of space. In the future research, we can study the temporal variation law of the coordination relation between two systems through data of different years, to provide more favorable data support for the future urban sustainable development.

(2) Try to use different models to measure the coordination between the two systems, such as through the analytic hierarchy process or coupling degree model to eliminate the possible deviation of the results.

(3) By introducing more abundant evaluation indicators, the traffic level can be represented by more diversified indicators such as traffic environment and traffic comfort. 


\section{Data Availability}

The built environment data are collected from API data disclosed by AutoNavi in 2019, and the traffic congestion data and traffic accident data are from the Traffic Big Data Bureau of Jinan.

\section{Conflicts of Interest}

The authors declare that they have no conflicts of interest.

\section{Acknowledgments}

This research was funded by Shandong Province Key Research and Development Project of China (no. GG201809240117).

\section{References}

[1] Y. Zhang and L. Guo, "Study on coordinated relationship between urban rail transit and land-use," International Conference on Logistics, IEEE, vol. 7, pp. 1-5, 2017.

[2] D. Huang, J. Xing, Z. Liu, and Q. An, "A multi-stage stochastic optimization approach to the stop-skipping and bus lane reservation schemes," Transportmetrica A: Transport Science, vol. 17, no. 4, pp. 1-33, 2020.

[3] Z. Liu, Y. Liu, C. Lyu, and J. Ye, "Building personalized transportation model for online taxi-hailing demand prediction," IEEE Transactions on Cybernetics, vol. 9, pp. 1-9, 2020.

[4] R. B. Mitchell and C. Rapkin, "Urban traffic: a function of land use," Population Studies, vol. 26, p. 226, 1954.

[5] V. G. Stover and Koepke, "Transportation and land development," United States, vol. 1, p. 239, 1987.

[6] S. Handy, "How land use patterns affect travel patterns: a bibliography," CPL Bibliography, vol. 3, p. 49, 1992.

[7] W. R. Black, Sustainable Transportation, The Guilford Press, New York, NY, USA, 2010.

[8] L. D. Frank, "Land use and transportation Interaction," Journal of Planning Education and Research, vol. 20, no. 1, pp. 6-22, 2000.

[9] R. Cervero and K. Kockelman, "Travel demand and the 3Ds: density, diversity, and design," Transportation Research Part D: Transport and Environment, vol. 2, no. 3, pp. 199-219, 1997.

[10] S. Handy, "Health and community design: the impact of the built environment on physical activity," Journal of the American Planning Association, vol. 70, pp. 375-376, 2004.

[11] R. Ewing and R. Cervero, "Travel and the built environment," Journal of the American Planning Association, vol. 76, no. 3, pp. 265-294, 2010.

[12] L. Liu, E. A. Silva, and Z. Yang, "Similar outcomes, different paths: tracing the relationship between neighborhood-scale built environment and travel behavior using activity-based modelling," Cities, vol. 110, Article ID 103061, 2021.

[13] L. Yong, "Study on the interaction between urban transportation system and land use in foreign countries," Tropical Geography, vol. 8, pp. 307-310, 1998.

[14] T. Shen, Y. Hong, M. M. Thompson, J. Liu, X. Huo, and $\mathrm{L}$. $\mathrm{Wu}$, "How does parking availability interplay with the land use and affect traffic congestion in urban areas? the case study of Xi'an, China," Sustainable Cities and Society, vol. 57, p. 102126, 2020.
[15] Y. Duan, K. Lei, H. Tong, B. Li, W. Wang, and Q. Hou, "Land use characteristics of Xi'an residential blocks based on pedestrian traffic system," Alexandria Engineering Journal, vol. 10, pp. 10-16, 2020.

[16] M. Guo and F. Kurauchi, "Changes in land use, transport system and traffic mobility in Gifu city during the 1980s and 1990s," Procedia - Social and Behavioral Sciences, vol. 138, pp. 537-547, 2014.

[17] B. van Wee, W. Bohte, E. Molin, T. Arentze, and F. Liao, "Policies for synchronization in the transport-land-use system," Transport Policy, vol. 31, pp. 1-9, 2014.

[18] W. Tu, Q. Li, Z. Fang, S.-1. Shaw, B. Zhou, and X. Chang, "Optimizing the locations of electric taxi charging stations: a spatial-temporal demand coverage approach," Transportation Research Part C: Emerging Technologies, vol. 65, pp. 172-189, 2016.

[19] C. Wu, X. Ye, F. Ren, and Q. Du, "Check-in behaviour and spatio-temporal vibrancy: an exploratory analysis in Shenzhen, China," Cities, vol. 77, pp. 104-116, 2018.

[20] J. A. Parry, S. A. Ganaie, and M. Sultan Bhat, "GIS based land suitability analysis using AHP model for urban services planning in Srinagar and Jammu urban centers of J\&K, India," Journal of Urban Management, vol. 7, no. 2, pp. 46-56, 2018.

[21] L. Wang, K. Wang, and J. Zhang, "Multiple objective-oriented land supply for sustainable transportation: a perspective from industrial dependence, dominance and restrictions of 127 cities in the yangtze river economic belt of China," Land Use Policy, vol. 99, Article ID 105069, 2020.

[22] R. Khare, V. G. K. Villuri, and D. Chaurasia, "Urban sustainability assessment: the evaluation of coordinated relation between BRTS and land use in transit-oriented development mode using DEA model," Ain Shams Engineering Journal, vol. 12, no. 1, pp. 107-117, 2020.

[23] X. Zhu, P. Zhang, Y. Wei, Y. Li, and H. Zhao, "Measuring the efficiency and driving factors of urban land use based on the DEA method and the PLS-SEM model-a case study of 35 large and medium-sized cities in China," Sustainable Cities and Society, vol. 50, Article ID 1010646, 2019.

[24] L. Yang, C. Shao, W. Nie, and Y. Zhao, "Evaluation on relation between urban transportation and land use based on TOD," Journal of Beijing Jiaotong University, vol. 31, no. 3, pp. 6-9, 2007.

[25] W. Wenjiang, Data Envelopment Analysis Models and its Application, China Statistics Press, Beijing, China, 2002.

[26] Y. Yang, B. Ma, and M. Koike, "Efficiency-measuring DEA model for production system with $k$ independent subsystems," Journal of the Operations Research Society of Japan, vol. 43, no. 3, pp. 343-354, 2000.

[27] Amor and T. Diez, "The efficiency of the Spanish police service: an application of the multiactivity DEA model," Applied Economics, vol. 4, pp. 351-362, 2010.

[28] W. K. S. Chin, "A neutral DEA model for cross-efficiency evaluation and its extension," Expert Systems with Applications, vol. 37, pp. 3666-3675, 2010.

[29] G.-M. Shi, J. Bi, and J.-N. Wang, "Chinese regional industrial energy efficiency evaluation based on a DEA model of fixing non-energy inputs," Energy Policy, vol. 38, no. 10, pp. 6172-6179, 2010.

[30] L. Susan, G. B. Marlon, E. Reid, and E. K. Richard, "How the built environment affects physical activity: views from urban planning," American Journal of Preventive Medicine, vol. 23, pp. 64-73, 2002.

[31] D. Huang, X. Chen, Z. Liu, C. Lyu, S. Wang, and X. Chen, “A static bike repositioning model in a hub-and-spoke network 
framework," Transportation Research Part E: Logistics and Transportation Review, vol. 141, Article ID 102031, 2020.

[32] B. Djsa and C. XD, "Spatiotemporal evolution of ridesourcing markets under the new restriction policy: a case study in Shanghai-ScienceDirect," Transportation Research Part A: Policy and Practice, vol. 130, pp. 227-239, 2019.

[33] Y. Lin, L. Li, H. Jing, B Ran, and D Sun, "Automated traffic incident detection with a smaller dataset based on generative adversarial networks," Accident; Analysis and Prevention, vol. 144, Article ID 105628, 2020.

[34] D. Sun, K. Zhang, and S. Shen, "Analyzing spatiotemporal traffic line source emissions based on massive didi online carhailing service data," Transportation Research Part D: Transport and Environment, vol. 62, pp. 699-714, 2018.

[35] Daniel, Jian, and Sun, "A bus route evaluation model based on GIS and super-efficient data envelopment analysis," Transportation Planning and Technology, vol. 39, no. 4, pp. 407-423, 2016.

[36] L. Li, J. Zhu, and H. Zhang, "Coupled application of generative adversarial networks and conventional neural networks for travel mode detection using GPS data," Transportation Research Part A: Policy and Practice, vol. 136, 2020.

[37] W. Y. Wang and J. C. Liu, "The coupling degree evaluation of Xi'an Subway station operation efficiency and surrounding land use based on DEA," Urban Public Transport, vol. 9, 2020. 